\title{
Predicting Role of Dosimetric Parameters for Nonclassic Radiation-Induced Liver Disease After Helical Tomotherapy in Child-Pugh Class a Primary Liver Carcinoma Patients
}

\section{Boyan Wang ( $D$ wangbyrt@126.com )}

Fudan University Shanghai Cancer Center https://orcid.org/0000-0002-3856-7032

Jianying Zhang

Zhongshan Hospital Fudan University

\section{Zhaochong Zeng}

Zhongshan Hospital Fudan University

\section{Research}

Keywords: primary liver carcinoma, helical tomotherapy, radiation-induced liver disease, Child-Pugh class A, mean dose to normal liver, dose-volume histogram

Posted Date: December 10th, 2020

DOl: https://doi.org/10.21203/rs.3.rs-123437/v1

License: (c) (1) This work is licensed under a Creative Commons Attribution 4.0 International License.

Read Full License 


\section{Abstract}

\section{Purpose}

This study sought to analyze the predicting role of dosimetric parameters for nonclassic radiationinduced liver disease (RILD) after helical tomotherapy (HT) in Child-Pugh (CP) class A primary liver carcinoma (PLC) patients.

Patients and methods

A total number of 71 CP class A PLC patients treated with HT from June 2011 to June 2015 were retrospectively reviewed. Clinical characteristics and dose-volume histogram (DVH) were recorded, and liver functions were followed up for 4 months after radiotherapy.

Results

In all, 57 patients $(80.3 \%)$ were male, and $14(19.7 \%)$ were female, with a median age of 53 years. The mean gross tumor volume (GTV) was $226.8 \mathrm{~cm}^{3}$. A median dose of $55.0 \mathrm{~Gy}$ was delivered by HT with a median fraction size of $2.6 \mathrm{~Gy}$. Twelve patients $(16.9 \%)$ were diagnosed with nonclassic RILD. The mean dose to normal liver (MDTNL) and the percentage of total liver volume receiving more than $25-35 \mathrm{~Gy}$ irradiations (V25 - V35) were related to nonclassic RILD. MDTNL showed the highest AUC $(0.705$, $p=0.026$ ). The optimal cut-off value of MDTNL was $21.3 \mathrm{~Gy}$ with a sensitivity, specificity and accuracy of $83.3 \%, 62.7 \%$ and $67.6 \%$, respectively. The tolerable volume percentages for DVH were less than: V25 of $42.3 \%, \mathrm{~V} 30$ of $33.9 \%$, and $\mathrm{V} 35$ of $28.3 \%$.

Conclusion

This study suggests that MDTNL, V25, V30 and V35 are dosimetric predictors for nonclassic RILD in CP class A PLC patients. MDTNL < 21.3Gy, V25 < 42.3\%, V30 < 33.9\%, and $\mathrm{V} 35<28.3 \%$ may be used to optimize HT planning.

\section{Background}

Primary liver carcinoma (PLC), the 6th most common cancer worldwide, occurs more common in men than in women (2.44:1). In male population, it is the second leading cause of cancer death.[1] Chinese patients account for about $50 \%$ of the total new liver cancer cases and deaths worldwide because of the prevalence of hepatitis B virus (HBV) infection. [1, 2] PLC is a heterogeneous disease, and treatment of liver cancer is multidisciplinary; multimodal treatment options are applied in clinic according to tumor stage as well as liver function. Although surgical resection or liver transplantation are standard treatment options for early stage PLC, many patients are inoperable at the time of diagnosis. In these patients, systemic therapies with sorafenib, regorafenib, lenvatinib, chemotherapy, immunotherapy, oncolytic virotherapy, and locoregional therapies with transarterial chemoembolization (TACE), radiofrequency ablation (RFA), percutaneous ethanol injection therapy (PEIT), radiotherapy (RT) have been used.[3-5] 
RT was not widely used historically due to the poor tolerance of the liver to radiation. Nowadays, technical advances in treatment design and delivery have ignited enthusiasm for RT as a potentially curative treatment modality. Since the National Comprehensive Cancer Network (NCCN) guidelines for hepatobiliary cancers version 2.2015, external-beam radiation therapy (EBRT) has been considered as a locoregional treatment option for patients with unresectable hepatocellular carcinoma (HCC) who are ineligible for transplantation, or who are inoperable owing to comorbidity.[6]

Radiation-induced liver disease (RILD) has long been reported as one of the most serious treatmentrelated complications for patients who undergo hepatic irradiation. There are few or no clinical symptoms associated with its early phase. It may result in liver failure and death, and treatment options are limited. [7] Therefore, RILD has become a major limitation of RT in the treatment of PLC, and preventive measures should be taken to avoid it. Despite various strategies are being investigated to prevent or minimize RILD, the most effective measure is probably to limit the liver dose within the tolerance range.[8]

Helical tomotherapy $(\mathrm{HT})$ is a precise RT modality that integrates intensity-modulated radiation therapy (IMRT) and image-guided radiation therapy (IGRT). It has benefit of improved dose conformity on the tumor with sparing the organs at risk (OARs).[9] HT can achieve better tumor coverage and deliver tumorcidal dosage more safely in PLC compared to three-dimensional conformal radiation therapy (3DCRT), and it differs from 3D-CRT in dose-volume histogram (DVH) parameters.[10, 11] Several studies have reported a number of predictors for RILD in PLC patients who underwent 3D-CRT.[12-16] Due to understanding of radiation tolerance dose of liver and the development of modern radiation delivery techniques, especially HT, classic RILD is very rare currently. The present study retrospectively evaluated RILD in 71 Child-Pugh (CP) class A PLC patients treated with HT and assessed dosimetric parameters that may predict nonclassic RILD.

\section{Materials And Methods}

\section{Study population}

Between June 2011 and June 2015, a total of 71 CP class A PLC patients who were treated with HT in the Department of Radiation Oncology at Zhongshan Hospital, Fudan University were enrolled in this study. This study was approved by the Medical Ethics Committee of Zhongshan Hospital. The inclusion criteria were as follows: (1) PLC patients with CP class A; (2) age > 18 years; (3) Eastern Cooperative Oncology Group (ECOG) performance score of 0,1 , or 2; (4) prior treatment by irradiation with HT; (5) no intrahepatic disease progression within 4 months after the completion of HT confirmed by magnetic resonance imaging (MRI). The patients' clinical characteristics that included gender, age, ECOG performance status, clinical stage, presence of HBV infection, diagnosis and previous treatments were displayed (Table 1). The clinical stage was determined by the American Joint Committee on Cancer (AJCC) Cancer Staging Manual, 8th edition.[17] The diagnosis of PLC was based on clinical diagnostic criteria proposed by the Society of Liver Cancer and Chinese Anti-Cancer Association in 2009.[18] 
Table 1

Clinical characteristics of PLC patients

\begin{tabular}{|c|c|c|c|c|}
\hline Variables & $\begin{array}{l}\text { Overall patients } \\
\text { (\%) }\end{array}$ & $\begin{array}{l}\text { Without nonclassic RILD } \\
\text { (\%) }\end{array}$ & $\begin{array}{l}\text { With nonclassic RILD } \\
\text { (\%) }\end{array}$ & $p$ \\
\hline & $N=71$ & $N=59$ & $N=12$ & \\
\hline Gender & & & & $0.564^{\square}$ \\
\hline Male & 57 (80.3) & 47 (79.7) & $10(83.3)$ & \\
\hline Female & $14(19.7)$ & $12(20.3)$ & $2(16.7)$ & \\
\hline Age (years) & & & & $0.223 \S$ \\
\hline Mean \pm SD & $55.3 \pm 12.2$ & $55.8 \pm 12.7$ & $51.1 \pm 9.4$ & \\
\hline Range & $22-86$ & $22-86$ & $38-71$ & \\
\hline ECOG & & & & $0.676^{\square}$ \\
\hline 1 & $60(84.5)$ & $49(83.1)$ & $11(91.7)$ & \\
\hline 2 & $11(15.5)$ & $10(16.9)$ & $1(8.3)$ & \\
\hline Clinical stage & & & & $0.193^{\square}$ \\
\hline$\nabla-\nabla$ & $25(35.2)$ & $23(39.0)$ & $2(16.7)$ & \\
\hline$\nabla-\nabla$ & $46(64.8)$ & $36(61.0)$ & $10(83.3)$ & \\
\hline HBV infection & & & & $0.739^{\square}$ \\
\hline Yes & $47(66.2)$ & $38(64.4)$ & $9(75.0)$ & \\
\hline No & $24(33.8)$ & $21(35.6)$ & $3(25.0)$ & \\
\hline Diagnosis & & & & $0.718^{\square}$ \\
\hline $\mathrm{HCC}$ & $54(76.1)$ & $44(74.6)$ & 10 (83.3) & \\
\hline ICC & $17(23.9)$ & $15(25.4)$ & $2(16.7)$ & \\
\hline $\begin{array}{l}\text { Previous } \\
\text { treatment }\end{array}$ & & & & $0.359^{\dagger}$ \\
\hline None & 13 (18.3) & $11(18.6)$ & $2(16.7)$ & \\
\hline Surgery & $34(47.9)$ & $27(45.8)$ & 7 (58.3) & \\
\hline TACE & $43(60.6)$ & 35 (59.3) & $8(66.7)$ & \\
\hline RFA & $12(16.9)$ & $12(20.3)$ & 0 & \\
\hline
\end{tabular}


For simulation and treatment, the patients were trained to breathe shallowly. Simulation was performed with enhanced computed tomography (CT) scan, and two additional series of CT scans during inspiration and expiration were obtained to track the motion of the tumors and other internal organs. The intrahepatic tumor with or without portal vein and/or inferior vena cava tumor thrombi were contoured as the gross tumor volume (GTV). The internal target volume (ITV) was defined as the summation of the GTVs on the inspiratory and expiratory CT images. The planning target volume (PTV) added a margin of $5 \mathrm{~mm}$ to the ITV to compensate for daily set-up errors and target motion.

The OARs were the liver, lungs, kidneys, spinal cord, heart, spleen, esophagus, stomach, duodenum and small bowels. The radiation dose was prescribed to the $95 \%$ isodose line encompassing the PTV. The HT was designed to deliver a median total dose of 55.0 Gy (range, 45.0-68.0 Gy) with 2.0-6.0 Gy fractions (2.0-2.2 Gy fractions in 14 patients, and 2.3-6.0 Gy fractions in 57 patients). And the treatment was delivered once per day, 5 times a week using Hi-ART system.

\section{Definition and evaluation of RILDEthics approval and consent to participate}

RILD occurring between 2 weeks and 4 months after completion of RT is separated into "classic" and "nonclassic" RILD. Classic RILD is defined as a triad of anicteric hepatomegaly, ascites, and elevated alkaline phosphatase (more than twice the upper limit of normal or baseline value).[19] Nonclassic RILD involves elevated liver transaminases (more than five times the upper limit of normal or baseline value), or a decline in liver function (measured by a worsening of CP score by 2 or more).[20, 21]

\section{Dosimetric parameters selection}

The dosimetric parameters involved in this study were the dose, fraction size, GTV, normal liver volume, mean dose to normal liver (MDTNL), liver volume, mean liver dose (MLD), the percentage of total liver volume receiving more than 5 Gy (V5), 10 Gy (V10), 15 Gy (V15), 20 Gy (V20), 25 Gy (V25), 30 Gy (V30), $35 \mathrm{~Gy}$ (V35), $40 \mathrm{~Gy}$ (V40), $45 \mathrm{~Gy}$ (V45), and $50 \mathrm{~Gy}$ (V50) (Table 2). These parameters were calculated on the basis of $\mathrm{DVH}$. 
Table 2

Dosimetric parameters of PLC patients

\begin{tabular}{|c|c|c|c|c|}
\hline Variables & $\begin{array}{l}\text { Overall patients } \\
\text { (Mean } \pm \text { SD (Range)) }\end{array}$ & $\begin{array}{l}\text { Without nonclassic } \\
\text { RILD } \\
\text { (Mean } \pm \text { SD (Range)) }\end{array}$ & $\begin{array}{l}\text { With nonclassic } \\
\text { RILD } \\
\text { (Mean } \pm \text { SD (Range)) }\end{array}$ & $p$ \\
\hline & $N=71$ & $N=59$ & $N=12$ & \\
\hline Dose (Gy) & $\begin{array}{l}55.1 \pm 5.4(45.0- \\
68.0)\end{array}$ & $54.7 \pm 5.4(45.0-68.0)$ & $\begin{array}{l}57.2 \pm 4.9(48.4- \\
64.0)\end{array}$ & $0.154^{\square}$ \\
\hline $\begin{array}{l}\text { Fraction size } \\
\text { (Gy) }\end{array}$ & & & & $0.564 \S$ \\
\hline $2.0-2.2$ & $14(19.7 \%)$ & $12(20.3 \%)$ & $2(16.7 \%)$ & \\
\hline $2.3-6.0$ & $57(80.3 \%)$ & $47(79.7 \%)$ & $10(83.3 \%)$ & \\
\hline $\operatorname{GTV}\left(\mathrm{cm}^{3}\right)$ & $\begin{array}{l}226.8 \pm 320.9(3.4- \\
1225.0)\end{array}$ & $\begin{array}{l}233.7 \pm 332.0(3.4- \\
1225.0)\end{array}$ & $\begin{array}{l}188.0 \pm 261.3(5.5- \\
856.0)\end{array}$ & $0.360^{\square}$ \\
\hline $\begin{array}{l}\text { Normal liver } \\
\text { volume } \\
\left(\mathrm{cm}^{3}\right)\end{array}$ & $\begin{array}{l}1195.7 \pm 277.1 \\
(808.4-1900.6)\end{array}$ & $\begin{array}{l}1223.8 \pm 264.4 \\
(808.4-1834.4)\end{array}$ & $\begin{array}{l}1164.4 \pm 273.1 \\
(831.3-1900.6)\end{array}$ & $0.699^{\square}$ \\
\hline MDTNL (Gy) & $19.8 \pm 5.9(6.8-29.8)$ & $19.1 \pm 6.1(6.8-29.8)$ & $\begin{array}{l}23.3 \pm 3.7(15.4- \\
28.1)\end{array}$ & $0.004^{\square}$ \\
\hline $\begin{array}{l}\text { Liver volume } \\
\left(\mathrm{cm}^{3}\right)\end{array}$ & $\begin{array}{l}1456.0 \pm 433.3 \\
(897.9-2934.9)\end{array}$ & $\begin{array}{l}1434.3 \pm 398.1 \\
(897.9-2934.9)\end{array}$ & $\begin{array}{l}1559.2 \pm 582.7 \\
(989.6-2799.2)\end{array}$ & $0.299^{\square}$ \\
\hline MLD (Gy) & $24.5 \pm 9.7(7.1-45.4)$ & $23.5 \pm 9.7(7.1-45.4)$ & $\begin{array}{l}29.4 \pm 8.5(16.9- \\
42.3)\end{array}$ & $0.054^{\square}$ \\
\hline V5 (\%) & $\begin{array}{l}77.2 \pm 15.2(39.8- \\
100.0)\end{array}$ & $\begin{array}{l}76.3 \pm 16.0(39.8- \\
100.0)\end{array}$ & $\begin{array}{l}81.7 \pm 9.0(61.3- \\
92.0)\end{array}$ & $0.114^{\square}$ \\
\hline V10 (\%) & $\begin{array}{l}64.7 \pm 17.7(22.6- \\
94.2)\end{array}$ & $\begin{array}{l}63.6 \pm 18.6(22.6- \\
94.2)\end{array}$ & $\begin{array}{l}69.9 \pm 11.2(47.5- \\
84.8)\end{array}$ & $0.133^{\square}$ \\
\hline V15 (\%) & $\begin{array}{l}55.9 \pm 18.9(12.8- \\
83.5)\end{array}$ & $\begin{array}{l}54.2 \pm 19.4(12.8- \\
82.9)\end{array}$ & $\begin{array}{l}63.9 \pm 14.0(38.1- \\
83.5)\end{array}$ & $0.105^{\square}$ \\
\hline V20 (\%) & $\begin{array}{l}48.0 \pm 20.3(7.4- \\
82.5)\end{array}$ & $45.8 \pm 20.4(7.4-79.4)$ & $\begin{array}{l}58.7 \pm 16.7(30.6- \\
82.5)\end{array}$ & $0.044^{\square}$ \\
\hline V25 (\%) & $\begin{array}{l}41.7 \pm 21.1(4.8- \\
81.5)\end{array}$ & $39.3 \pm 21.0(4.8-75.4)$ & $\begin{array}{l}53.4 \pm 18.0(24.3- \\
81.5)\end{array}$ & $0.034^{\square}$ \\
\hline V30 (\%) & $\begin{array}{l}36.5 \pm 21.3(3.5- \\
80.1)\end{array}$ & $34.1 \pm 21.1(3.5-73.2)$ & $\begin{array}{l}48.3 \pm 19.0(19.8- \\
80.1)\end{array}$ & $0.034^{\square}$ \\
\hline V35 (\%) & $\begin{array}{l}32.0 \pm 21.1(2.8- \\
78.3)\end{array}$ & $29.7 \pm 20.7(2.8-71.1)$ & $\begin{array}{l}43.3 \pm 20.3(16.0- \\
78.3)\end{array}$ & $0.041^{\square}$ \\
\hline
\end{tabular}




\begin{tabular}{|c|c|c|c|c|}
\hline Variables & $\begin{array}{l}\text { Overall patients } \\
\text { (Mean } \pm \text { SD (Range)) }\end{array}$ & $\begin{array}{l}\text { Without nonclassic } \\
\text { RILD } \\
\text { (Mean } \pm \text { SD (Range)) }\end{array}$ & $\begin{array}{l}\text { With nonclassic } \\
\text { RILD } \\
\text { (Mean } \pm \text { SD (Range)) }\end{array}$ & $p$ \\
\hline V40 (\%) & $\begin{array}{l}27.9 \pm 20.4(2.1- \\
74.8)\end{array}$ & $25.7 \pm 19.7(2.1-68.1)$ & $\begin{array}{l}38.4 \pm 21.2(12.1- \\
74.8)\end{array}$ & $0.049^{\square}$ \\
\hline V45 (\%) & $\begin{array}{l}23.4 \pm 19.0(1.6- \\
64.7)\end{array}$ & $21.7 \pm 18.6(1.6-62.5)$ & $\begin{array}{l}31.8 \pm 19.2(7.6- \\
64.7)\end{array}$ & $0.094^{\square}$ \\
\hline V50 (\%) & $17.6 \pm 17.1(0-61.7)$ & $16.5 \pm 16.5(0-56.2)$ & $\begin{array}{l}22.9 \pm 19.6(1.3- \\
61.7)\end{array}$ & $0.240^{\square}$ \\
\hline
\end{tabular}

\section{Statistical analyses}

Student's t-test, Fisher's exact test and Mann-Whitney U test were used to compare clinical characteristics and dosimetric parameters of patients with nonclassic RILD and without nonclassic RILD. Univariate binary logistic regression models were used to evaluate the relationship between clinical / dosimetric parameters and nonclassic RILD. Linear regression models were applied to analyze the correlations among variables of DVH. The dosimetric predictors for nonclassic RILD were estimated by the logistic model and receiver operating characteristic (ROC) curve. The statistical analyses were performed using IBM SPSS Statistics (version 20.0; IBM Corp, Armonk, NY) and a $p$ value of $<0.05$ was considered to be statistically significant.

\section{Results}

Of the 71 patients, 3 patients (4.2\%) developed both classic and nonclassic RILD, and 9 patients (12.7\%) developed nonclassic RILD alone. Among the 12 patients with nonclassic RILD, all had elevated liver transaminases, and $2(16.7 \%)$ had a worsening of CP score by $\geq 2$. The interval to the development of nonclassic RILD ranged from 2 weeks to 4 months (median, 3 months) after HT completion.

Univariate binary logistic regression models were used to evaluate the associations between the clinical / dosimetric parameters and nonclassic RILD, and the statistically significant variables were displayed (Table 3). The correlation of clinical parameters with nonclassic RILD was not detected. Of the dosimetric parameters, MDTNL, V25, V30 and V35 were associated with nonclassic RILD. 
Table 3

Univariate analyses of dosimetric parameters in patients with or without nonclassic RILD

\begin{tabular}{|llll|}
\hline Variables & $\boldsymbol{p}$ & OR & $95 \% \mathrm{Cl}$ \\
\hline MDTNL & 0.032 & 1.153 & $1.012-1.314$ \\
\hline V25 & 0.042 & 1.034 & $1.001-1.068$ \\
\hline V30 & 0.042 & 1.033 & $1.001-1.065$ \\
\hline V35 & 0.048 & 1.031 & $1.000-1.063$ \\
\hline Notes: $p$ value was tested from univariate binary logistical regression model (method: Enter). \\
\hline
\end{tabular}

The estimated probability curves of nonclassic RILD were presented (Fig. 1). It was shown that the probability of nonclassic RILD was in proportion to MDTNL. The parameters of V25, V30 and V35 also had similar relationship patterns. However, these estimated probability curves did not indicate the cut-off value for predicting nonclassic RILD. Considering the high correlation coefficient $(r)$ among these variables according to the correlation analyses (MDTNL vs. V25, $r=0.854, p<0.001$; MDTNL vs. V30, $r=$ $0.824, p<0.001$; MDTNL vs. V35, $r=0.793, p<0.001$; V25 vs. V30, $r=0.994, p<0.001 ; \mathrm{V} 25$ vs. V35, $r=$ $0.978, p<0.001 ; \mathrm{V} 30 \mathrm{vs}$. V35, $r=0.994, p<0.001)$, the multivariate analysis containing these variables was not reliable.

We further tested the predictability of each parameter for nonclassic RILD with the ROC curve, and the area under the curve (AUC) showed meaningful results (Table 4 and Fig. 2). MDTNL showed the highest AUC (0.705) with a sensitivity of $83.3 \%$ and a specificity of $62.7 \%$. Nonclassic RILD was observed in 2 of 40 patients $(5.0 \%)$ with MDTNL $<21.3 \mathrm{~Gy}$, and in 10 of 31 patients $(32.3 \%)$ with MDTNL $\geq 21.3 \mathrm{~Gy}$. For MDTNL with a cut-off value of $21.3 \mathrm{~Gy}$, the accuracy was $67.6 \%(48 / 71)$.

Table 4

ROC curve for dosimetric parameters

\begin{tabular}{|llllll|}
\hline Variables & AUC & Cut-off Value & Sensitivity & Specificity & $\boldsymbol{p}$ \\
\hline MDTNL & 0.705 & 21.3 & 0.833 & 0.627 & 0.026 \\
\hline V25 & 0.701 & 42.3 & 0.750 & 0.610 & 0.029 \\
\hline V30 & 0.703 & 33.9 & 0.833 & 0.593 & 0.027 \\
\hline V35 & 0.699 & 28.3 & 0.750 & 0.593 & 0.007 \\
\hline
\end{tabular}

\section{Discussion}

HT has facilitated IGRT system using daily CT image guidance and IMRT delivery using continuously rotating 6-MV linear accelerator and dynamically positioned multileaf collimator.[22, 23] With the advent of $\mathrm{HT}$, irradiation of an entire huge PLC or multiple targets can be safely performed with sparing the normal OARs.[24] HT is critical in improving local control and providing a survival benefit as a therapeutic 
option for PLC.[10, 25] It is vital to reduce the probability of RILD when a hepatic irradiation therapy plan is designed. Effective predictors for RILD are required to optimize HT planning, while the published data on RILD after HT in PLC is limited do date.

Classic RILD is considered to be the lethal treatment-related complication for PLC patients and it is very rare in the era of HT. MLD as an important risk factor of classic RILD in 3D-CRT has been well demonstrated in previous publications. Dawson et al.[12] suggested that MLD associated with a $5 \%$ risk of classic RILD for primary and metastatic liver cancer were $28 \mathrm{~Gy}$ and $32 \mathrm{~Gy}$, respectively. The patients with unresectable intrahepatic cancer were treated using 3D-CRT, and no case of RILD occurred when MLD was less than 31 Gy.[13] Nonclassic RILD is much more common than classic type in PLC patients treated with HT. The incidence of nonclassic RILD in our study was $16.9 \%(12 / 71)$. We found that MDTNL of 21.3 Gy was tolerable in HT for CP class A PLC cases: the incidence of nonclassic RILD was $5.0 \%$ $(2 / 40)$ for patients with MDTNL < 21.3 Gy and 32.3\% (10/31) for those with MDTNL $\geq 21.3 \mathrm{~Gy}$. MDTNL is the mean dose delivered to the normal liver, whereas MLD is given to the whole liver. The reason why the dose threshold that we recommend is lower than those of previous studies[12,13] might lie in the background of hepatitis B and liver cirrhosis.

Prior reports have shown that RILD concerned with hepatitis B and liver function status. HBV carriers and CP class B significantly correlated to great susceptibility to RILD after 3D-CRT: the incidence of RILD was $33.3 \%$ for patients with CP class B and $14.7 \%$ for patients with CP class A, and RILD was observed in $24.6 \%$ of HBV carrier patients, but only in $4.2 \%$ of non-carrier patients.[14] An association between pretreatment liver function and the risk of RILD after SBRT has also been reported. The CP class B cirrhosis was found to have great susceptibility to the development of RILD in HCC patients treated with SBRT.[26] CP score was a significant factor related to liver toxicity and RILD could be tolerated by patients with a CP score not more than seven.[27] In the current study, nonclassic RILD developed more often in HBV carrier patients than in non-carrier patients (19.1\% vs. $12.5 \%)$, but this difference was not statistically significant. Considering that the CP class of enrolled patients was A, the relationship between RILD and liver function status was not detected. We still recommend that it is necessary to monitor liver function carefully during and after HT.

Furthermore, clinical researches have demonstrated that DVH played an important role in the determination of RILD. The percentage of normal liver volume receiving more than $20 \mathrm{~Gy}\left(\mathrm{~V}_{20}\right)$ of $48.5 \%$ and the percentage of total liver volume receiving more than $30 \mathrm{~Gy}\left({ }_{\mathrm{TL}} \mathrm{V}_{30 \mathrm{~Gy}}\right)$ of $60 \%$ were useful dosimetric predictors for RILD in PLC patients after 3D-CRT.[15, 16] Due to the difference of dose distribution between HT and 3D-CRT treatment plans,[25] dosimetric parameters of predicting RILD for HT treatment plans are also needed. The percentage of non-target normal liver volume receiving more than $15 \mathrm{~Gy}\left(\mathrm{~V}_{15 \mathrm{~Gy}}\right)<43.2 \%$ and receiving more than a biological equivalent dose (BED) of $20 \mathrm{~Gy}\left(\mathrm{~V}_{\mathrm{BED} 20}\right)<$ $40.8 \%$ were recommended to reduce the risk of RILD in HCC patients after HT.[28, 29] Our results provided that V25, V30 and V35 were associated with nonclassic RILD in the univariate analyses, and these findings may be implemental to design, assess and optimize HT treatment plans. 


\section{Conclusions}

In sum, due to RILD is a serious complication, prevention measures are of paramount importance. MDTNL may be a valuable dosimetric predictor for nonclassic RILD risk in CP class A PLC patients after HT. MDTNL $<21.3 \mathrm{~Gy}, \mathrm{~V} 25<42.3 \%, \mathrm{~V} 30<33.9 \%$, and $\mathrm{V} 35<28.3 \%$ can be used as reference, and these data may provide useful information in clinical practice. However, further investigation is required to validate the extensive applicability and practical significance of our observations via a larger number of patients with greater homogeneity.

\section{Abbreviations}

primary liver carcinoma (PLC), hepatitis B virus (HBV), transarterial chemoembolization (TACE), radiofrequency ablation (RFA), percutaneous ethanol injection therapy (PEIT), radiotherapy (RT), National Comprehensive Cancer Network (NCCN), external-beam radiation therapy (EBRT), hepatocellular carcinoma (HCC), radiation-induced liver disease (RILD), helical tomotherapy (HT), intensity-modulated radiation therapy (IMRT), image-guided radiation therapy (IGRT), organ at risk (OAR), three-dimensional conformal radiation therapy (3D-CRT), dose-volume histogram (DVH), Child-Pugh (CP), Eastern Cooperative Oncology Group (ECOG), magnetic resonance imaging (MRI), American Joint Committee on Cancer (AJCC), computed tomography (CT), gross tumor volume (GTV), internal target volume (ITV), planning target volume (PTV), mean dose to normal liver (MDTNL), mean liver dose (MLD), receiver operating characteristic (ROC), area under the curve (AUC).

\section{Declarations}

\section{Ethics approval and consent to participate}

This study was approved by the Medical Ethics Committee of Zhongshan Hospital, and informed consent was obtained from all patients.

\section{Consent for publication Availability of data and materials}

Consent for publication was obtained from all patients.

\section{Availability of data and materials}

The datasets used and/or analysed during the current study are available from the corresponding author on reasonable request.

\section{Competing interests}


The authors report no conflicts of interest in this work.

\section{Funding}

Not applicable.

\section{Authors' Contributions}

WBY and ZZC have contributed to the conception, study design, execution and interpretation. WBY and ZJY collected and analyzed the data. WBY drafted the manuscript. ZZC and ZJY critically reviewed the article. All authors agreed to take responsibility and be accountable for the contents of the article. All authors read and approved the final manuscript.

\section{Acknowledgments}

Not applicable.

\section{References}

1. Bray F, Ferlay J, Soerjomataram I, Siegel RL, Torre LA, Jemal A. Global cancer statistics 2018 : GLOBOCAN estimates of incidence and mortality worldwide for 36 cancers in 185 countries. CA Cancer J Clin. 2018;68(6): 394-424.

2. Chen W, Zheng R, Baade PD, Zhang S, Zeng H, Bray F, et al. Cancer statistics in China, 2015. CA Cancer J Clin. 2016;66(2): 115-132.

3. Heimbach JK, Kulik LM, Finn RS, Sirlin CB, Abecassis MM, Roberts LR, et al. AASLD guidelines for the treatment of hepatocellular carcinoma. Hepatology. 2018;67(1): 358-380.

4. European Association for the Study of the Liver. EASL Clinical Practice Guidelines: Management of hepatocellular carcinoma. J Hepatol. 2018;69(1): 182-236.

5. Omata M, Cheng AL, Kokudo N, Kudo M, Lee JM, Jia J, et al. Asia-Pacific clinical practice guidelines on the management of hepatocellular carcinoma: a 2017 update. Hepatol Int. 2017;11(4): 317-370.

6. National Comprehensive Cancer Network. NCCN clinical practice guidelines in oncology, hepatobiliary cancers 2015 [Online, 06 Oct 2015]. 2015 Fort Washington, PA.

7. Guha C, Kavanagh BD. Hepatic radiation toxicity: avoidance and amelioration. Semin Radiat Oncol. 2011;21(4): 256-263.

8. Koay EJ, Owen D, Das P. Radiation-Induced Liver Disease and Modern Radiotherapy. Semin Radiat Oncol. 2018;28(4): 321-331.

9. Rong Y, Welsh JS. Dosimetric and clinical review of helical tomotherapy. Expert Rev Anticancer Ther. 2011;11(2): 309-320. 
10. Huang CM, Huang MY, Tang JY, Chen SC, Wang LY, Lin ZY, et al. Feasibility and efficacy of helical tomotherapy in cirrhotic patients with unresectable hepatocellular carcinoma. World J Surg Oncol. 2015;13: 201.

11. Lee IJ, Seong J, Koom WS, Kim YB, Jeon BC, Kim JH, et al. Selection of the optimal radiotherapy technique for locally advanced hepatocellular carcinoma. Jpn J Clin Oncol. 2011;41(7): 882-889.

12. Dawson LA, Ten Haken RK. Partial volume tolerance of the liver to radiation. Semin Radiat Oncol. 2005;15(4): 279-283.

13. Dawson LA, Normolle D, Balter JM, McGinn CJ, Lawrence TS, Ten Haken RK. Analysis of radiationinduced liver disease using the Lyman NTCP model. Int J Radiat Oncol Biol Phys. 2002;53(4): 810821.

14. Cheng JC, Wu JK, Lee PC, Liu HS, Jian JJ, Lin YM, et al. Biologic susceptibility of hepatocellular carcinoma patients treated with radiotherapy to radiation-induced liver disease. Int J Radiat Oncol Biol Phys. 2004;60(5): 1502-1509.

15. Liang SX, Huang XB, Zhu XD, Zhang WD, Cai L, Huang HZ, et al. Dosimetric predictor identification for radiation-induced liver disease after hypofractionated conformal radiotherapy for primary liver carcinoma patients with Child-Pugh Grade A cirrhosis. Radiother Oncol. 2011;98(2): 265-269.

16. Kim TH, Kim DY, Park JW, Kim SH, Choi JI, Kim HB, et al. Dose-volumetric parameters predicting radiation-induced hepatic toxicity in unresectable hepatocellular carcinoma patients treated with three-dimensional conformal radiotherapy. Int J Radiat Oncol Biol Phys. 2007;67(1): 225-231.

17. American Joint Committee on Cancer. AJCC Cancer Staging Manual. 8th ed. 2016 New York, USA: Springer.

18. Ye SL. Expert consensus on standardization of the management of primary liver cancer. Zhonghua Gan Zang Bing Za Zhi. 2009;17(6): 403-410.

19. Lawrence TS, Robertson JM, Anscher MS, Jirtle RL, Ensminger WD, Fajardo LF. Hepatic toxicity resulting from cancer treatment. Int J Radiat Oncol Biol Phys. 1995;31(5): 1237-1248.

20. Pan CC, Kavanagh BD, Dawson LA, Li XA, Das SK, Miften M, et al. Radiation-associated liver injury. Int J Radiat Oncol Biol Phys. 2010;76(Suppl 3): S94-S100.

21. Song JH, Jeong BK, Choi HS, Jeong H, Lee YH, Kim HJ, et al. Defining Radiation-Induced Hepatic Toxicity in Hepatocellular Carcinoma Patients Treated with Stereotactic Body Radiotherapy. J Cancer. 2017;8(19): 4155-4161.

22. Kim JY, Yoo EJ, Jang JW, Kwon JH, Kim KJ, Kay CS. Hypofractionated radiotheapy using helical tomotherapy for advanced hepatocellular carcinoma with portal vein tumor thrombosis. Radiat Oncol. 2013;8: 15.

23. Yoon HI, Lee IJ, Han KH, Seong J. Improved oncologic outcomes with image-guided intensitymodulated radiation therapy using helical tomotherapy in locally advanced hepatocellular carcinoma. J Cancer Res Clin Oncol. 2014;140(9): 1595-1605.

24. Jang JW, Kay CS, You CR, Kim CW, Bae SH, Choi JY, et al. Simultaneous multitarget irradiation using helical tomotherapy for advanced hepatocellular carcinoma with multiple extrahepatic metastases. 
Int J Radiat Oncol Biol Phys. 2009;74(2): 412-418.

25. Hou JZ, Zeng ZC, Wang BL, Yang P, Zhang JY, Mo HF. High dose radiotherapy with image-guided hypo-IMRT for hepatocellular carcinoma with portal vein and/or inferior vena cava tumor thrombi is more feasible and efficacious than conventional 3D-CRT. Jpn J Clin Oncol. 2016;46(4): 357-362.

26. Jung J, Yoon SM, Kim SY, Cho B, Park JH, Kim SS, et al. Radiation-induced liver disease after stereotactic body radiotherapy for small hepatocellular carcinoma: clinical and dose-volumetric parameters. Radiat Oncol. 2013;8: 249.

27. Jun BG, Kim YD, Cheon GJ, Kim ES, Jwa E, Kim SG, et al. Clinical significance of radiation-induced liver disease after stereotactic body radiation therapy for hepatocellular carcinoma. Korean $\mathrm{J}$ Intern Med. 2018;33(6): 1093-1102.

28. Son SH, Kay CS, Song JH, Lee SW, Choi BO, Kang YN, et al. Dosimetric parameter predicting the deterioration of hepatic function after helical tomotherapy in patients with unresectable locally advanced hepatocellular carcinoma. Radiat Oncol. 2013;8: 11.

29. Song JH, Son SH, Kay CS, Jang HS. Identification of Biologically Effective Dose-Volumetric Parameters That Predict Radiation-Induced Hepatic Toxicity in Patients Treated With Helical Tomotherapy for Unresectable Locally Advanced Hepatocellular Carcinoma. Medicine (Baltimore). 2015;94(43): e1904.

\section{Tables}

Table 1. Clinical characteristics of PLC patients 


\begin{tabular}{|c|c|c|c|c|}
\hline Variables & $\begin{array}{l}\text { Overall patients } \\
(\%)\end{array}$ & $\begin{array}{l}\text { Without nonclassic RILD } \\
(\%)\end{array}$ & $\begin{array}{l}\text { With nonclassic RILD } \\
(\%)\end{array}$ & $p$ \\
\hline & $N=71$ & $N=59$ & $\mathrm{~N}=12$ & \\
\hline Gender & & & & $0.564^{\square}$ \\
\hline Male & 57 (80.3) & 47 (79.7) & 10 (83.3) & \\
\hline Female & $14(19.7)$ & $12(20.3)$ & $2(16.7)$ & \\
\hline Age (years) & & & & $0.223 \S$ \\
\hline Mean \pm SD & $55.3 \pm 12.2$ & $55.8 \pm 12.7$ & $51.1 \pm 9.4$ & \\
\hline Range & $22-86$ & $22-86$ & $38-71$ & \\
\hline ECOG & & & & $0.676^{\square}$ \\
\hline 1 & $60(84.5)$ & $49(83.1)$ & $11(91.7)$ & \\
\hline 2 & $11(15.5)$ & $10(16.9)$ & $1(8.3)$ & \\
\hline Clinical stage & & & & $0.193^{\square}$ \\
\hline$\nabla-\nabla$ & $25(35.2)$ & $23(39.0)$ & $2(16.7)$ & \\
\hline$\nabla-\nabla$ & $46(64.8)$ & $36(61.0)$ & 10 (83.3) & \\
\hline HBV infection & & & & $0.739^{\square}$ \\
\hline Yes & $47(66.2)$ & $38(64.4)$ & $9(75.0)$ & \\
\hline No & $24(33.8)$ & $21(35.6)$ & $3(25.0)$ & \\
\hline Diagnosis & & & & $0.718^{\square}$ \\
\hline $\mathrm{HCC}$ & $54(76.1)$ & $44(74.6)$ & $10(83.3)$ & \\
\hline ICC & $17(23.9)$ & $15(25.4)$ & $2(16.7)$ & \\
\hline $\begin{array}{l}\text { Previous } \\
\text { treatment }\end{array}$ & & & & $0.359^{\dagger}$ \\
\hline None & 13 (18.3) & $11(18.6)$ & $2(16.7)$ & \\
\hline Surgery & $34(47.9)$ & $27(45.8)$ & 7 (58.3) & \\
\hline TACE & $43(60.6)$ & 35 (59.3) & $8(66.7)$ & \\
\hline RFA & $12(16.9)$ & $12(20.3)$ & 0 & \\
\hline
\end{tabular}

Notes: $p$ value was tested from Fisher's exact test. 
- $p$ value was tested from Student's t-test.

${ }^{\dagger} p$ value was tested from Mann-Whitney $\mathrm{U}$ test.

Abbreviations: PLC, primary liver carcinoma; RILD, radiation-induced liver disease; SD, standard deviation; ECOG, Eastern Cooperative Oncology Group; HBV, hepatitis B virus; HCC, hepatocellular carcinoma; ICC, intrahepatic cholangiocarcinoma; TACE, transarterial chemoembolization; RFA, radiofrequency ablation.

\section{Table 2. Dosimetric parameters of PLC patients}




\begin{tabular}{|c|c|c|c|c|}
\hline Variables & $\begin{array}{l}\text { Overall patients } \\
(\text { Mean } \pm \text { SD (Range)) }\end{array}$ & $\begin{array}{l}\text { Without nonclassic } \\
\text { RILD } \\
(\text { Mean } \pm \text { SD (Range)) }\end{array}$ & $\begin{array}{l}\text { With nonclassic RILD } \\
(\text { Mean } \pm \text { SD }(\text { Range }))\end{array}$ & $p$ \\
\hline & $N=71$ & $N=59$ & $\mathrm{~N}=12$ & \\
\hline Dose (Gy) & $\begin{array}{l}55.1 \pm 5.4(45.0- \\
68.0)\end{array}$ & $\begin{array}{l}54.7 \pm 5.4(45.0- \\
68.0)\end{array}$ & $\begin{array}{l}57.2 \pm 4.9(48.4- \\
64.0)\end{array}$ & $0.154^{\square}$ \\
\hline $\begin{array}{l}\text { Fraction size } \\
\text { (Gy) }\end{array}$ & & & & $0.564 \S$ \\
\hline $2.0-2.2$ & $14(19.7 \%)$ & $12(20.3 \%)$ & $2(16.7 \%)$ & \\
\hline $2.3-6.0$ & $57(80.3 \%)$ & $47(79.7 \%)$ & $10(83.3 \%)$ & \\
\hline $\operatorname{GTV}\left(\mathrm{cm}^{3}\right)$ & $\begin{array}{l}226.8 \pm 320.9(3.4- \\
1225.0)\end{array}$ & $\begin{array}{l}233.7 \pm 332.0(3.4- \\
1225.0)\end{array}$ & $\begin{array}{l}188.0 \pm 261.3(5.5- \\
856.0)\end{array}$ & $0.360^{\square}$ \\
\hline $\begin{array}{l}\text { Normal liver } \\
\text { volume } \\
\left(\mathrm{cm}^{3}\right)\end{array}$ & $\begin{array}{l}1195.7 \pm 277.1 \\
(808.4-1900.6)\end{array}$ & $\begin{array}{l}1223.8 \pm 264.4 \\
(808.4-1834.4)\end{array}$ & $\begin{array}{l}1164.4 \pm 273.1 \\
(831.3-1900.6)\end{array}$ & $0.699^{\square}$ \\
\hline MDTNL (Gy) & $19.8 \pm 5.9(6.8-29.8)$ & $19.1 \pm 6.1(6.8-29.8)$ & $\begin{array}{l}23.3 \pm 3.7(15.4- \\
28.1)\end{array}$ & $0.004^{\square}$ \\
\hline $\begin{array}{l}\text { Liver volume } \\
\left(\mathrm{cm}^{3}\right)\end{array}$ & $\begin{array}{l}1456.0 \pm 433.3 \\
(897.9-2934.9)\end{array}$ & $\begin{array}{l}1434.3 \pm 398.1 \\
(897.9-2934.9)\end{array}$ & $\begin{array}{l}1559.2 \pm 582.7 \\
(989.6-2799.2)\end{array}$ & $0.299^{\square}$ \\
\hline MLD (Gy) & $24.5 \pm 9.7(7.1-45.4)$ & $23.5 \pm 9.7(7.1-45.4)$ & $\begin{array}{l}29.4 \pm 8.5(16.9- \\
42.3)\end{array}$ & $0.054^{\square}$ \\
\hline V5 (\%) & $\begin{array}{l}77.2 \pm 15.2(39.8- \\
100.0)\end{array}$ & $\begin{array}{l}76.3 \pm 16.0(39.8- \\
100.0)\end{array}$ & $\begin{array}{l}81.7 \pm 9.0(61.3- \\
92.0)\end{array}$ & $0.114^{\square}$ \\
\hline V10 (\%) & $\begin{array}{l}64.7 \pm 17.7(22.6- \\
94.2)\end{array}$ & $\begin{array}{l}63.6 \pm 18.6(22.6- \\
94.2)\end{array}$ & $\begin{array}{l}69.9 \pm 11.2(47.5- \\
84.8)\end{array}$ & $0.133^{\square}$ \\
\hline V15 (\%) & $\begin{array}{l}55.9 \pm 18.9(12.8- \\
83.5)\end{array}$ & $\begin{array}{l}54.2 \pm 19.4(12.8- \\
82.9)\end{array}$ & $\begin{array}{l}63.9 \pm 14.0(38.1- \\
83.5)\end{array}$ & $0.105^{\square}$ \\
\hline V20 (\%) & $\begin{array}{l}48.0 \pm 20.3(7.4- \\
82.5)\end{array}$ & $\begin{array}{l}45.8 \pm 20.4(7.4- \\
79.4)\end{array}$ & $\begin{array}{l}58.7 \pm 16.7(30.6- \\
82.5)\end{array}$ & $0.044^{\square}$ \\
\hline V25 (\%) & $\begin{array}{l}41.7 \pm 21.1(4.8- \\
81.5)\end{array}$ & $\begin{array}{l}39.3 \pm 21.0(4.8- \\
75.4)\end{array}$ & $\begin{array}{l}53.4 \pm 18.0(24.3- \\
81.5)\end{array}$ & $0.034^{\square}$ \\
\hline V30 (\%) & $\begin{array}{l}36.5 \pm 21.3(3.5- \\
80.1)\end{array}$ & $\begin{array}{l}34.1 \pm 21.1(3.5- \\
73.2)\end{array}$ & $\begin{array}{l}48.3 \pm 19.0(19.8- \\
80.1)\end{array}$ & $0.034^{\square}$ \\
\hline V35 (\%) & $\begin{array}{l}32.0 \pm 21.1(2.8- \\
78.3)\end{array}$ & $\begin{array}{l}29.7 \pm 20.7(2.8- \\
71.1)\end{array}$ & $\begin{array}{l}43.3 \pm 20.3(16.0- \\
78.3)\end{array}$ & $0.041^{\square}$ \\
\hline V40 (\%) & $\begin{array}{l}27.9 \pm 20.4(2.1- \\
74.8)\end{array}$ & $\begin{array}{l}25.7 \pm 19.7(2.1- \\
68.1)\end{array}$ & $\begin{array}{l}38.4 \pm 21.2(12.1- \\
74.8)\end{array}$ & $0.049^{\square}$ \\
\hline
\end{tabular}




\begin{tabular}{|lllll|}
\hline V45 (\%) & $23.4 \pm 19.0(1.6-$ & $21.7 \pm 18.6(1.6-$ & $31.8 \pm 19.2(7.6-$ & $0.094^{\square}$ \\
& $64.7)$ & $62.5)$ & $64.7)$ & \\
\hline V50 (\%) & $17.6 \pm 17.1(0-61.7)$ & $16.5 \pm 16.5(0-56.2)$ & $22.9 \pm 19.6(1.3-$ & $0.240^{\square}$ \\
& & & $61.7)$ & \\
\hline
\end{tabular}

Notes: ${ }^{\square} p$ value was tested from Student’s t-test.

- $p$ value was tested from Fisher's exact test.

Abbreviations: RILD, radiation-induced liver disease; SD, standard deviation; GTV, gross tumor volume; MDTNL, mean dose to normal liver; MLD, mean liver dose; VX, percentage of total liver volume receiving more than X Gy

Table 3. Univariate analyses of dosimetric parameters in patients with or without nonclassic RILD

\begin{tabular}{|llll|}
\hline Variables & $p$ & OR & $95 \% \mathrm{Cl}$ \\
\hline MDTNL & 0.032 & 1.153 & $1.012-1.314$ \\
\hline V25 & 0.042 & 1.034 & $1.001-1.068$ \\
\hline V30 & 0.042 & 1.033 & $1.001-1.065$ \\
\hline V35 & 0.048 & 1.031 & $1.000-1.063$ \\
\hline
\end{tabular}

Notes: $p$ value was tested from univariate binary logistical regression model (method: Enter).

Abbreviations: RILD, radiation-induced liver disease; OR, odds ratio; $\mathrm{Cl}$, Confidence Interval; MDTNL, mean dose to normal liver; VX, percentage of total liver volume receiving more than X Gy.

Table 4. ROC curve for dosimetric parameters

\begin{tabular}{|llllll|}
\hline Variables & AUC & Cut-off Value & Sensitivity & Specificity & $p$ \\
\hline MDTNL & 0.705 & 21.3 & 0.833 & 0.627 & 0.026 \\
\hline V25 & 0.701 & 42.3 & 0.750 & 0.610 & 0.029 \\
\hline V30 & 0.703 & 33.9 & 0.833 & 0.593 & 0.027 \\
\hline V35 & 0.699 & 28.3 & 0.750 & 0.593 & 0.007 \\
\hline
\end{tabular}

Notes: $p$ value was tested from Student's t-test.

Abbreviations: ROC, receiver operating characteristic; AUC, area under the curve; MDTNL, mean dose to normal liver; VX, percentage of total liver volume receiving more than X Gy. 


\section{Figures}
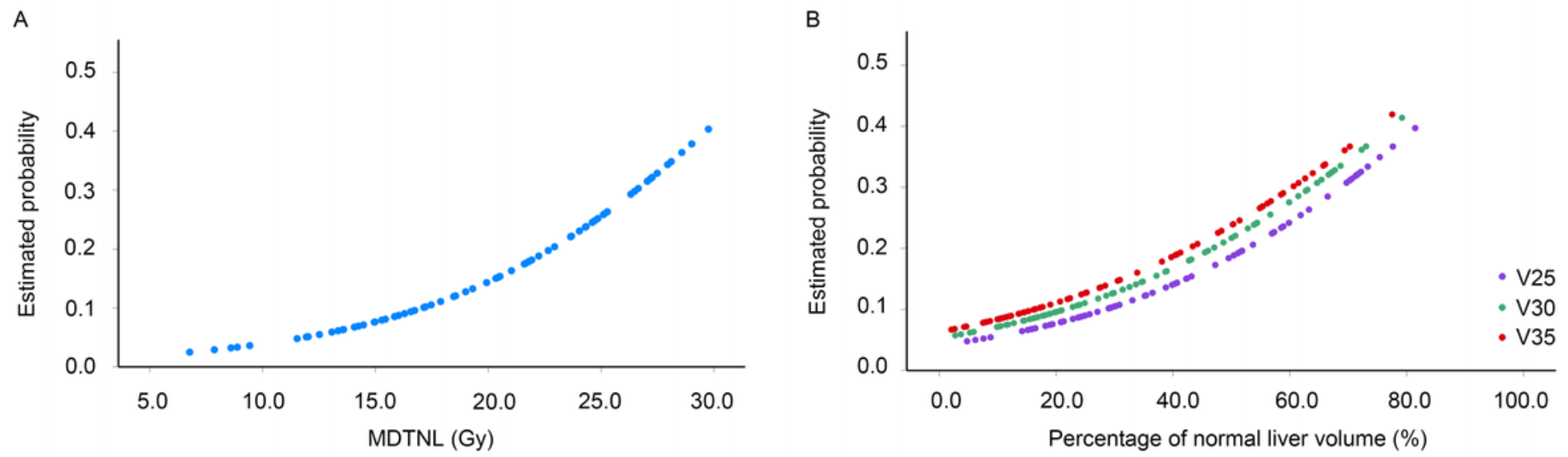

\section{Figure 1}

Estimated probability curves of nonclassic RILD for dosimetric parameters. (A) Estimated probability curve of nonclassic RILD for MDTNL. (B) Estimated probability curves of nonclassic RILD for V25, V30 and V35.
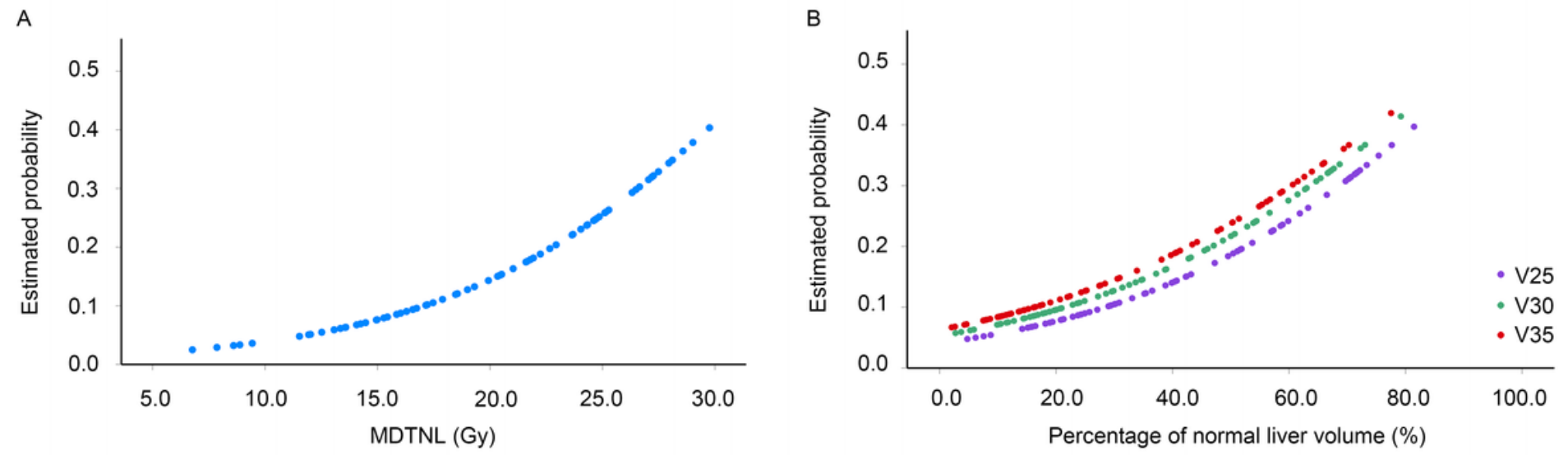

\section{Figure 1}

Estimated probability curves of nonclassic RILD for dosimetric parameters. (A) Estimated probability curve of nonclassic RILD for MDTNL. (B) Estimated probability curves of nonclassic RILD for V25, V30 and V35. 
A

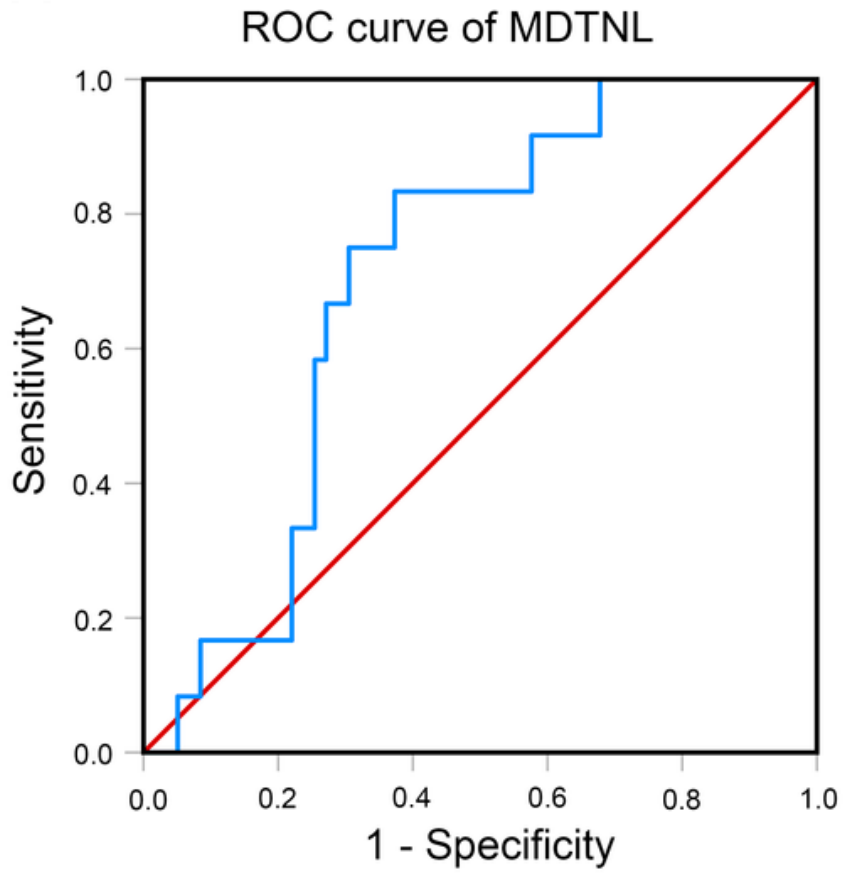

C

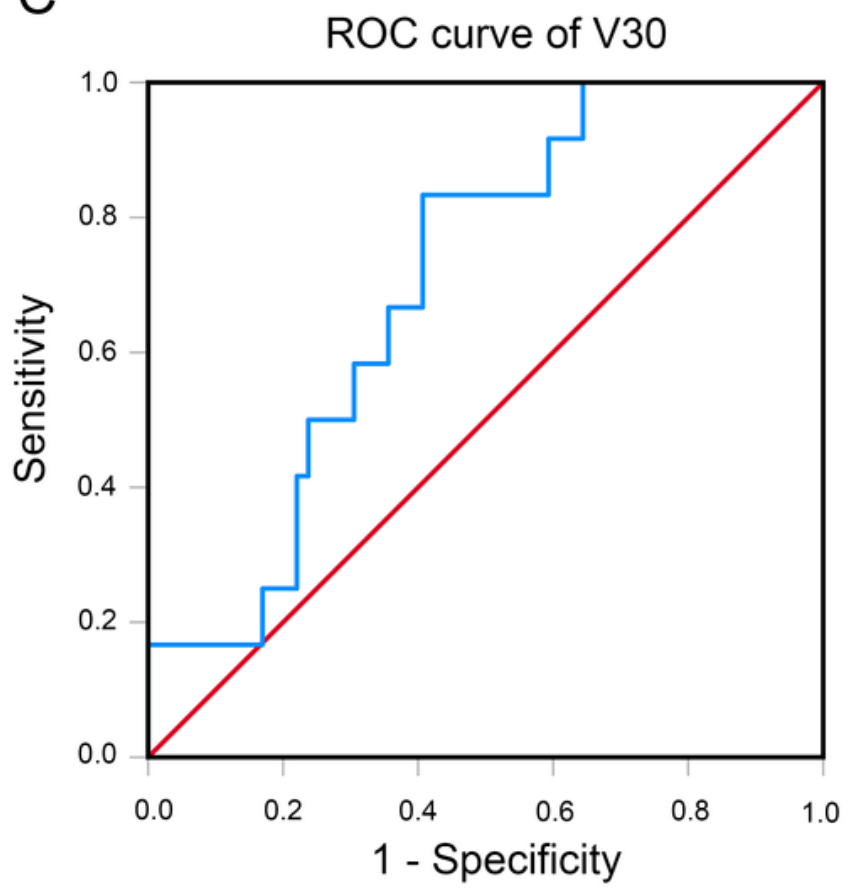

$\mathrm{B}$

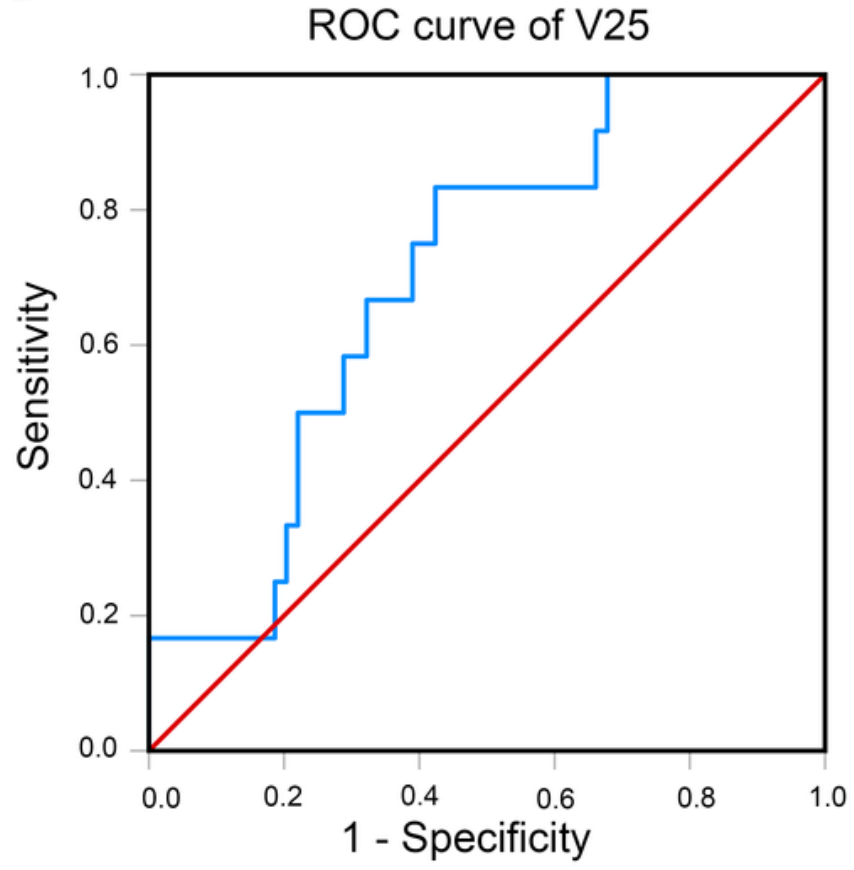

D

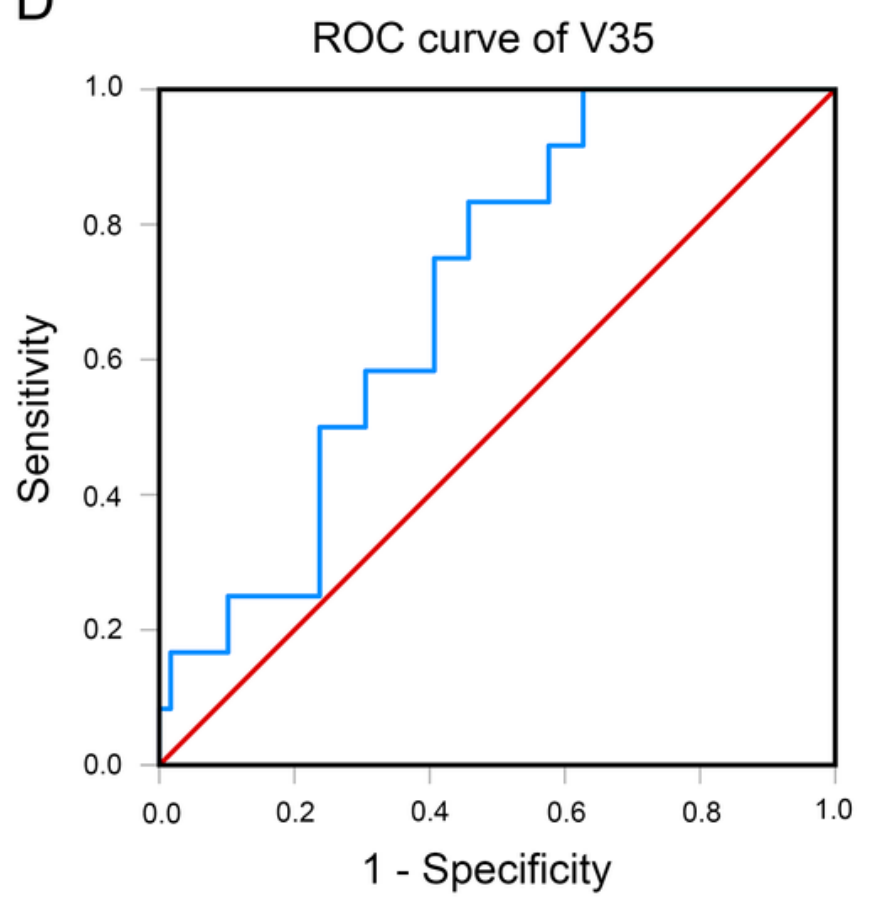

Figure 2

ROC curves of dosimetric parameters. ROC curves of MDTNL (A), V25 (B), V30(C) and V35(D). 
A

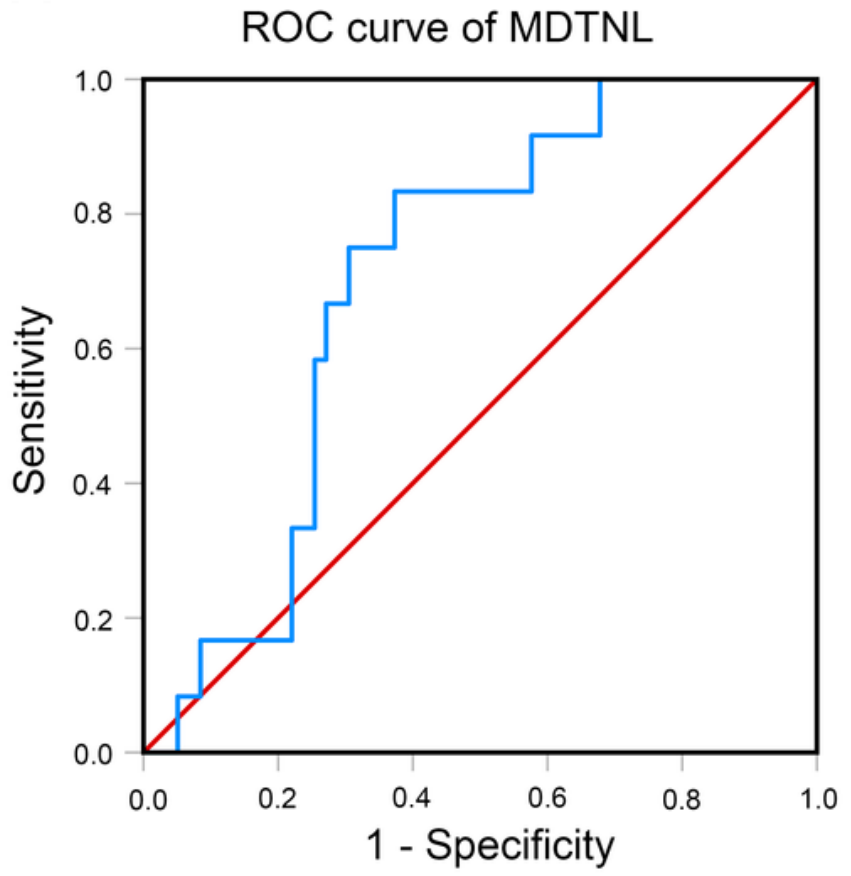

C

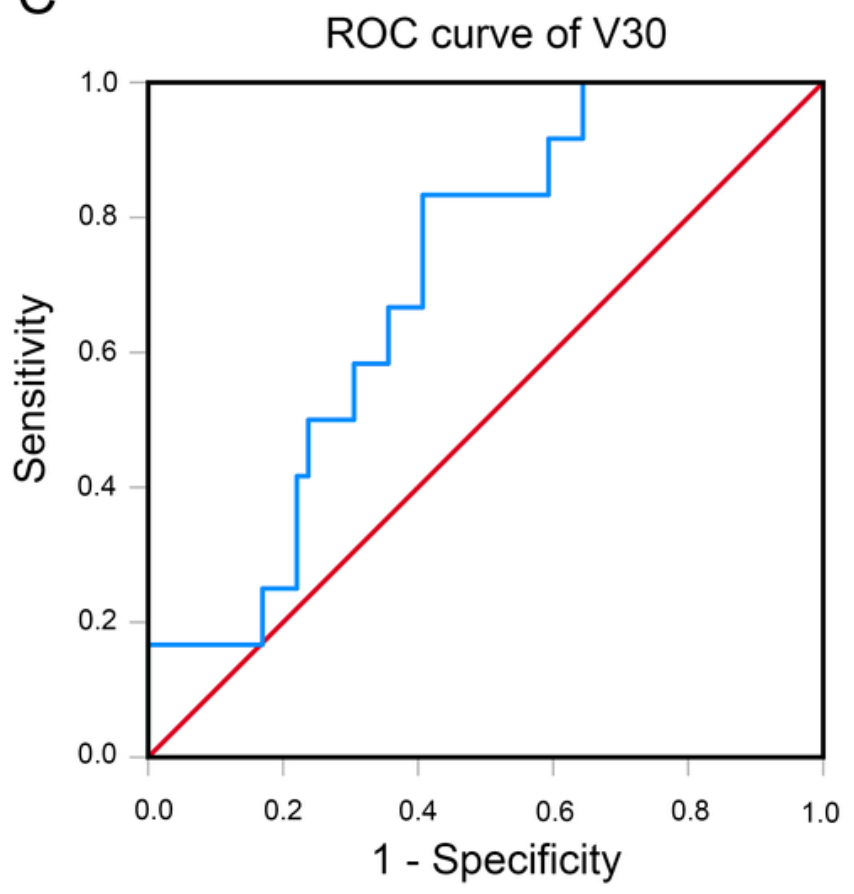

$\mathrm{B}$

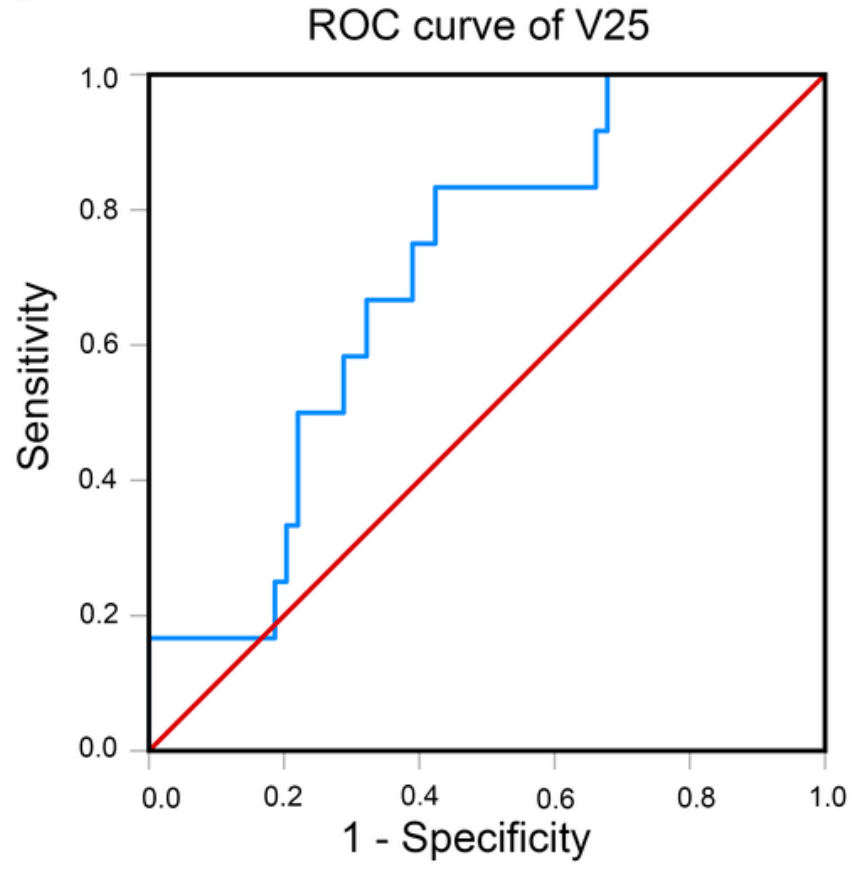

D

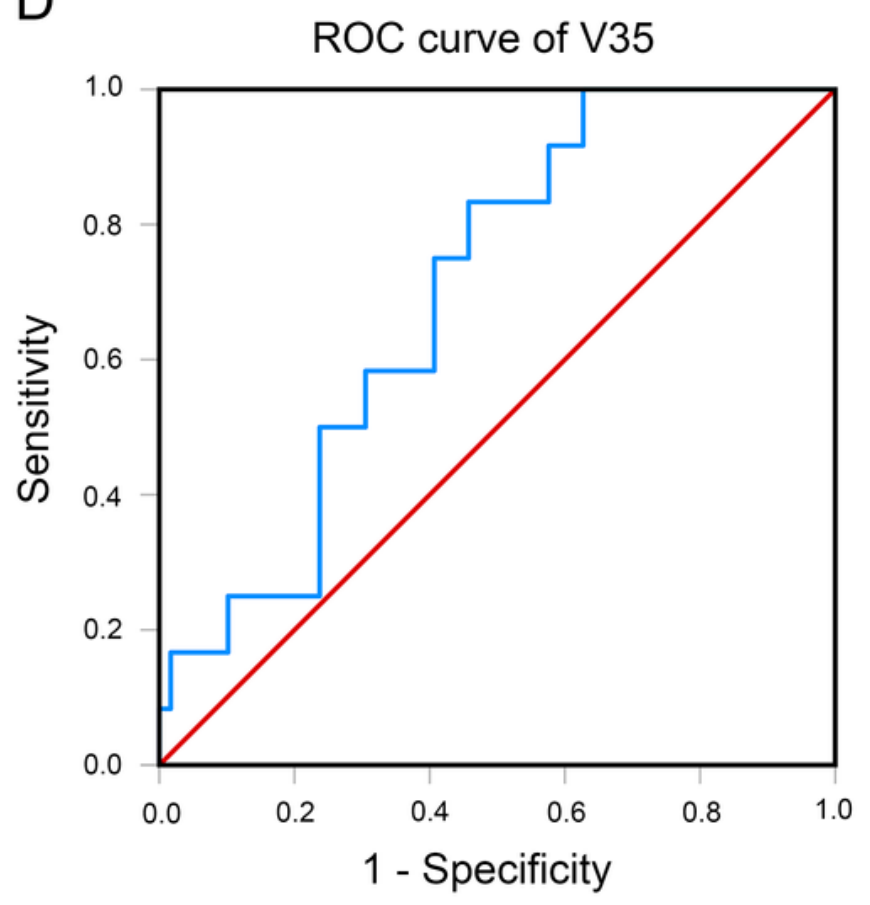

Figure 2

ROC curves of dosimetric parameters. ROC curves of MDTNL (A), V25 (B), V30(C) and V35(D). 